https://doi.org/10.15407/ujpe63.4.333

L.A. BULAVIN, L.YU. VERGUN, YU.F. ZABASHTA, O.S. SVECHNIKOVA

Taras Shevchenko National University of Kyiv, Faculty of Physics, Chair of Molecular Physics (4, Academician Glushkov Ave., Kyiv 03022, Ukraine; e-mail: bulavin221@gmail.com, verlen73@ukr.net, oksana.svechnikova@gmail.com)

\title{
MECHANISM OF INTERACTION \\ BETWEEN THE BOUNDARY LAYER OF A POLYMER MEMBRANE AND A GAS ENVIRONMENT
}

\begin{abstract}
The initial stage at the penetration of air molecules through a polymer membrane has been studied experimentally. A transient process giving rise to an equilibrium between the gas and the boundary layer of the membrane is revealed. This process looks like damped pressure oscillations associated with a periodic shape changes of polymer chains in the boundary layer driven by the "ball-globule" transition. A hypothesis is put forward that a similar phenomenon governs the influence of atmospheric pressure variations on the human organism.

Keywords: gas permeability, "ball-globule" transition, boundary layer.
\end{abstract}

\section{Introduction}

When speaking about the membrane, we mean a film that is made up of a certain substance and separates two regions filled with other substances. Let the concentrations of molecules of a certain kind (below, they will be conventionally referred to as foreign ones) in those mentioned regions be equal to $c_{1}$ and $c_{2}$. Due to the concentration difference $\left(c_{1} \neq c_{2}\right)$, the molecules move through the membrane. The ability of the membrane to let these molecules to pass through it is called the permeability with respect to the indicated kind of molecules.

The behavior of a membrane is usually described using a model, in which the membrane is regarded as a certain continuum confined between two infinite planes located at $x=0$ and $x=l$, where $l$ is the membrane thickness. The motion of molecules through the membrane is described by the diffusion equation

$\frac{\partial c}{\partial t}=D \frac{\partial^{2} c}{\partial x^{2}}$

(c) L.A. BULAVIN, L.YU. VERGUN, YU.F. ZABASHTA, O.S. SVECHNIKOVA, 2018

ISSN 2071-0194. Ukr. J. Phys. 2018. Vol. 63, No. 4 where $c$ is the molecular concentration, $t$ the time, and $D$ the diffusion coefficient.

If the concentrations in the regions contacting with the membrane are maintained to equal $c_{1}$ and $c_{2}$, the diffusion in the membrane occurs under the boundary conditions

$c(x=0)=c_{1}^{\prime}$,

$c(x=l)=c_{2}^{\prime}$.

It is important that the concentrations $c_{1}^{\prime}$ and $c_{2}^{\prime}$ are not equal to the concentrations $c_{1}$ and $c_{2}$ in the regions contacting with the membrane. If the membrane is brought into contact with a medium, where the concentration is equal to $c_{1}$, then the concentration value $c_{1}^{\prime}$ in the plane $x=0$, which is in contact with this medium, is established only after a certain time interval $\tau$. The process of establishing the molecular concentration at the membrane boundary will be referred to as a transient process, and the magnitude of $\tau$ as a transient period.

The aim of this work is to determine the physical mechanism of the transition process in polymer membranes. 


\section{Experimental Part}

Synthetic membranes, more specifically, oligourethane acrylate polymer films, are studied. Data about their structure can be found in work [1]. The film thickness was $0.78 \mathrm{~mm}$. The gas permeability of those membranes is analyzed.

The schematic diagram of the experimental installation is shown in Fig. 1. The installation included a fixed base 1 , working chamber 2 , film specimen 3 , system of connected glass tubes 4, valves 5 to 8 , pump 9, manometer 10 , thermocouple 11 with a heater, thermocouple 12 with a heat controller 13 , and power source 14 .

The schematic diagram of a working chamber is shown in Fig 2. The polymer film 1 together with sealing gaskets 2 was pressed to the working cham-

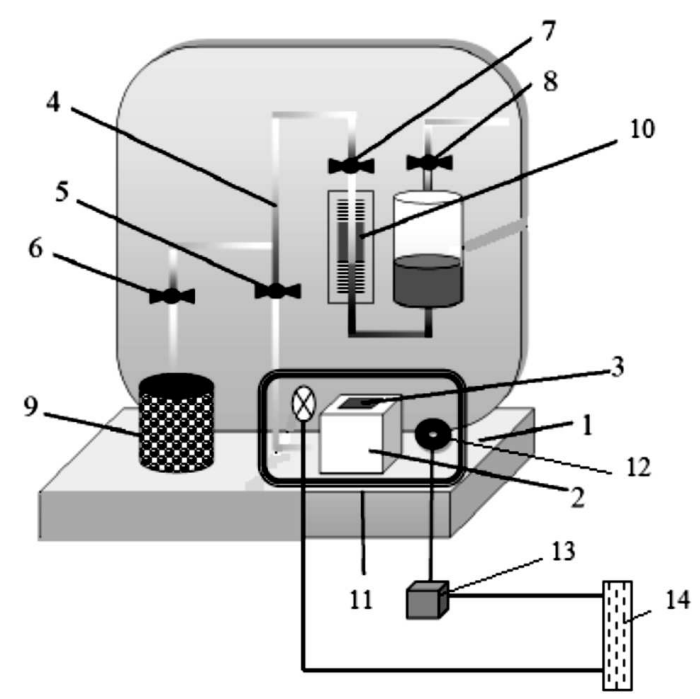

Fig. 1. Schematic diagram of the experimental installation

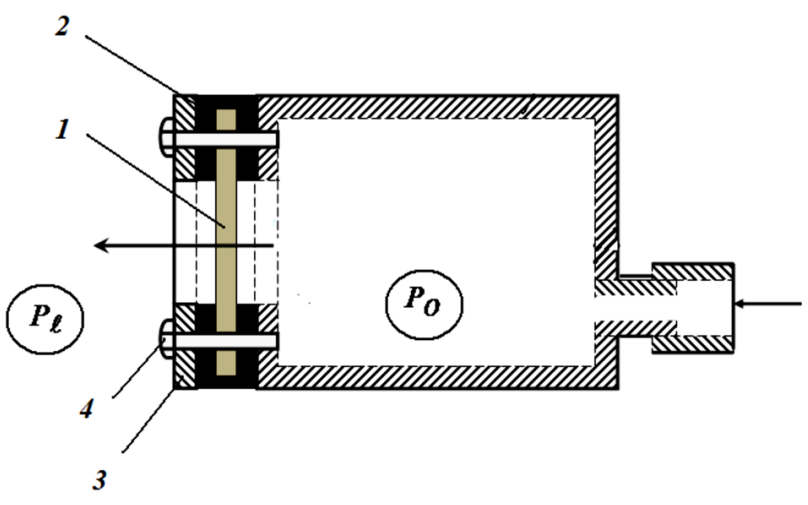

Fig. 2. Schematic diagram of a working chamber

334 ber surface using plate 3 and screws 4 . In this experiment, air was a substance that contacted with the membrane, so that the volumes filled with air served as reservoirs of foreign molecules.

With the help of pump 9 (Fig. 1), the pressure $P_{0}$ exceeding the atmospheric pressure $P_{l}$ was created in the working chamber. Then valve 6 was shut, and the variation of the excess pressure was measured. The pressure varied owing to the diffusion of foreign molecules through the polymer membrane. The excess pressure $P=P_{0}-P_{l}$ was measured by means of manometer 10 (Fig. 1). The corresponding measurement error was $\pm 5 \mathrm{~Pa}$. The time dependences $P=P(t)$ obtained at various temperatures are shown in Fig. 3.

From this figure, it is evident that two stages can be distinguished in the dependences $P(t)$. At the first, initial, stage, variations of $P$ are observed. At the second stage, the values of $P$ remain almost constant. In our opinion, it is reasonable to connect the first stage with a transient process, and the second one with the process of stationary diffusion described by Eq. (1). The constancy of the pressure $P$ at the second stage can be explained by low velocities of diffusing molecules. The period $\tau$ of the transient process should be considered as the duration of the first stage. Figure 4 illustrates the dependence of the transient period $\tau$ on the temperature $T$. The measurement error for $\tau$ amounted to $\pm 1 \mathrm{~min}$. One can see that the period $\tau$ decreases, as the temperature grows.

\section{Thermodynamics of the Transient Process}

When determining the mechanism of the transient process, the first-priority issue concerns the membrane section, where this process takes place. As was already mentioned, to describe the penetration of foreign molecules through a membrane, a continuum model for the latter is used as a rule. In the framework of this model, the transient process occurs at the membrane boundary, which is considered to be a plane. It is clear that this is an abstraction, because, in a real physical system instead of such a "plane", we have the layer of a certain substance with finite thickness, which is conventionally called the boundary layer. Hence. we arrive at a conclusion that the transient process takes place in the boundary layer of the membrane.

ISSN 2071-0194. Ukr. J. Phys. 2018. Vol. 63, No. 4 


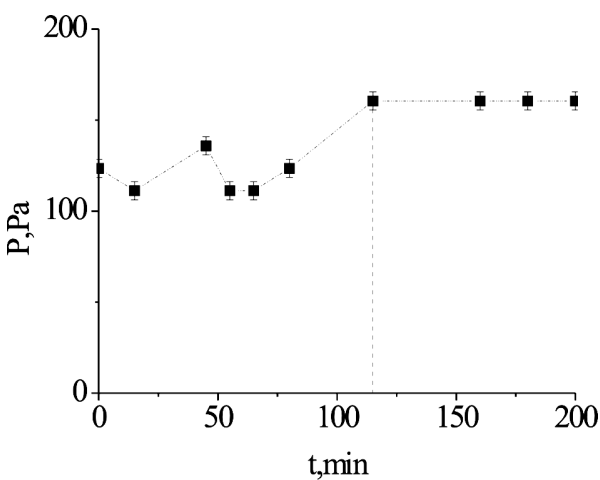

$a$

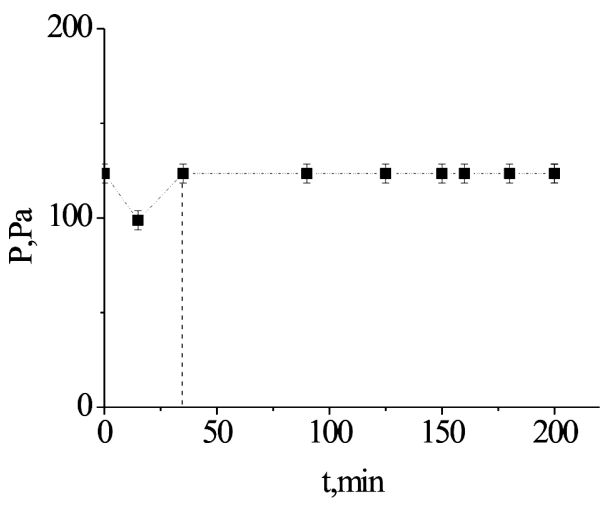

$c$
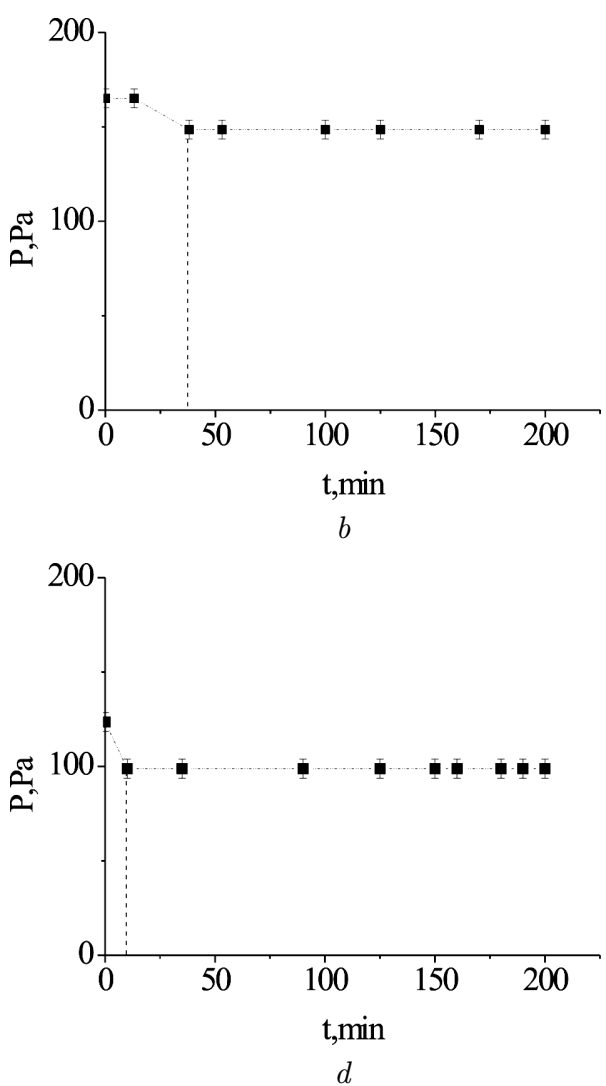

Fig. 3. Time dependences of the excess pressure $P$ at various temperatures: $298(a), 303(b)$, $313(c)$, and $318 \mathrm{~K}(d)$

Air is known to consist of molecules of several kinds. In this work, approximately, it will be considered as a gas with only one kind of molecules, which we call foreign.

Let the coordinates $x=0$ and $x=l$ in the continuum model correspond to the left and right surfaces of the membrane (see Fig. 2). We are interested in the right surface that contacts with the medium, where the pressure $P_{0}$ is higher. The transient process analyzed below is nothing else but the establishment of the concentration $c_{2}^{\prime}$ of foreign molecules in the boundary layer adjacent to $x=l$.

Assuming the gas to be ideal, we write down

$P_{0}=c_{2} k_{\mathrm{B}} T$.

The chemical potential $\mu_{0}$ of the gas molecules is described by the formula (see, e.g., work [2])

$\mu_{0}=k_{\mathrm{B}} T \ln P_{0}+X(T)$,



Fig. 4. Temperature dependence of the transition period $\tau$ where $X(T)$ is a certain function of the temperature $T$.

The substance that the boundary layer is made of is considered to be a solid solution of foreign molecules in a polymer. For the chemical potential $\mu$ of foreign molecules in the boundary layer, we have

$\mu=k_{\mathrm{B}} T \ell n c_{2}^{\prime}+\Psi\left(P_{1}, T\right)$, 


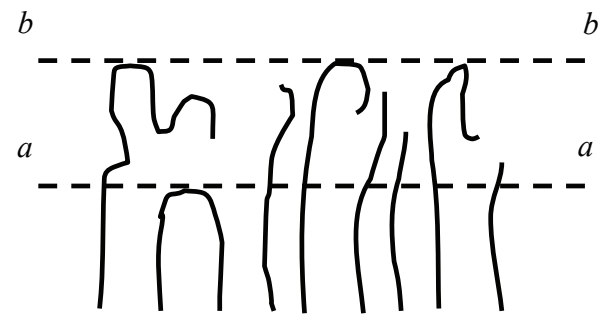

Fig. 5. Schematic structure of the boundary layer

where $\Psi\left(P_{1}, T\right)$ is a certain function of the pressure $P_{1}$ and the temperature $T$.

The transient process terminates, when an equilibrium is established between the gas and the boundary layer, i.e. provided

$\mu_{0}=\mu$.

It is clear that the incomplete equilibrium is implied, which is established within the period $\tau$. This equilibrium is ensured by the hierarchy of relaxation times

$\tau \ll \tau_{l}$,

where

$\tau_{l} \approx \ell^{2} / D$

is the characteristic time of the diffusion process.

\section{Molecular Mechanism of the Transient Process}

It is known (see, e.g., work [3]) that the boundary layer of a polymer is substantially disordered. Its structure is schematically exhibited in Fig. 5. The boundary layer is denoted by two dashed lines, $a a$ and $b b$. It contains a significant number of cavities, which allows the chains in the boundary layer to acquire a natural ball shape (see, e.g., work [3]).

However, unlike an isolated ball, fluctuations of the balls in the boundary layer are restricted to some extent by the presence of the aa surface (Fig. 5), to which the polymer chains are attached, and by neighbor chains. Using the approach expounded in work [4], the indicated restriction can be taken into consideration in the framework of the "chain-in-pore" model. According to the latter, the pressure $P_{S}$ of the chain on the pore wall is determined by the formula

$P_{S} \sim k_{\mathrm{B}} T N a^{2} D^{-5}$, where $N$ is the number of links in the chain, $a$ the link size, and $D$ the pore size.

According to this formula, for $T \approx 300 \mathrm{~K}, N \approx 100$, $a \approx 10^{-10} \mathrm{~cm}$, and $D \approx 10^{-9} \mathrm{~m}$, the pressure is evaluated as $P_{S} \approx 10^{6} \mathrm{~Pa}$. This value obtained for the pressure in the polymer pore is much larger than the change of the external pressure on the polymer membrane. Therefore, under the indicated conditions, the structure of the membrane boundary layer can vary only if the thermodynamic state of the system is in a vicinity of the "ball-globule" phase transition point. In this case, the chain state may become unstable with respect to the action of external forces. Then the application of even a small external pressure, like $P$, may play the role of a trigger to start the mentioned phase transition.

As one can see from Fig. 3, in the experiment, after the pressure $P$ had been applied, changes of its values were observed. This fact means that the phase transition obtains a periodic character. As is known from the theory of nonlinear oscillations (see, e.g., work [5]), if the equilibrium state of the system becomes unstable, there may arise oscillations in the latter. In our opinion, the observed changes of the $P$-values are manifestations of such oscillations.

The emergence of oscillations under the conditions of the "ball-globule" phase transition means that the chain periodically changes its shape, namely, the ball transforms into a globule and vice versa. Accordingly, the chemical potential $\mu$ also changes, and, when it becomes larger than $\mu_{0}$, there arises a flux of foreign molecules from the boundary layer, which increases the observed value of $P$. Then the inequality $\mu_{0}>\mu$ induces a reverse flux, which decreases the value of $P$.

Generally speaking, the foreign molecules were in the boundary layer even before the excess pressure was applied. In the course of the mentioned phase transition, there can emerge such thermodynamic conditions that those molecules will make the pressure in a working chamber higher than the initial excess pressure, as is illustrated in Fig. 3, a. According to this figure, the corresponding excess amounts to $25 \mathrm{~Pa}$. At first glance, it is impossible to obtain the indicated value with the help of foreign molecules from the boundary layer. Really, if we use the gas state equation (3) to calculate the number of molecules required to create a pressure of $25 \mathrm{~Pa}$, we will find that the boundary layer must almost entirely consist of foreign molecules.

ISSN 2071-0194. Ukr. J. Phys. 2018. Vol. 63, No. 4 
However, this result does not contradict the proposed mechanism of the transient process, where the latter is associated with the "ball-globul" transitions. Every ball is known to be a fractal structure [4]. The polymer links constitute less than three percent of its volume. All other space can be occupied by foreign molecules. On the other hand, in a globule, the links are closely packed to one another. For this reason, the globule is called the non-periodic crystal. Therefore, in the course of the "ball-globule" transition, all foreign molecules located in the ball are thrown away into a working chamber, which was observed in the experiment.

The interaction between the polymer chain and the environment results in the attenuation of oscillations concerned. The period $\tau$ is the experimentally observed time interval, during which the oscillations died at various temperatures. The temperature growth increases the oscillation energy absorption by the environment. Therefore, it is natural that the period $\tau$ decreases, as the temperature grows, as was found in the described experiment (Fig. 4).

\section{Transient Process \\ in the Boundary Layer of a Biological Membrane. Plasmalemma}

The word plasmalemma is used (see, e.g., work [6]) to denote the external cell membrane that encloses the cell and provides its exchange with the environment. The plasmalemma is composed (see Fig. 6) of a lipoprotein complex 1 and a glycocalyx 2. The lipoprotein complex is formed by a double layer of lipid molecules 3 penetrated by protein molecules 4. The glycocalyx has branched polysaccharide chains 5 attached to the protein and lipid molecules of the membrane.

As one can see from Fig. 6, the glycocalyx is nothing else but the boundary layer of the membrane introduced by us. Its structure is similar to that of the boundary layer in the synthetic membrane. As in the case of synthetic membrane, the boundary layer of a biological membrane is formed by polymer chains, which, due to a disorder in this layer, have enough free space to form balls. The latter, under certain conditions, can transform into globules.

The marked similarity between the structures of boundary layers in the synthetic and biological membranes makes it possible to assume that the mech-

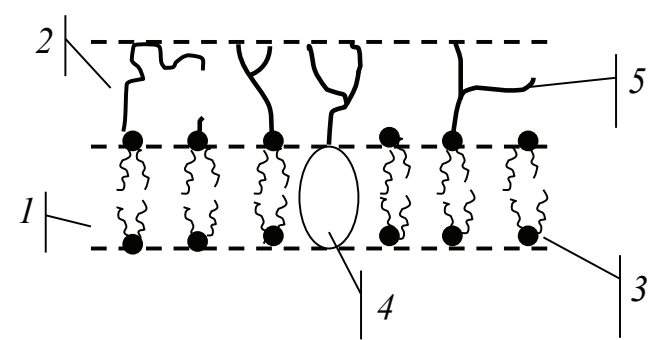

Fig. 6. Schematic structure of plasmalemma

anisms of transient processes in the membranes of both types are also similar. In particular, the biological membrane, like the synthetic one, should "feel" small variations of the external pressure, because they affect the transient process in the boundary layer. Perhaps, in this case, we deal with one of the mechanisms that govern the influence of changes in the atmospheric pressure on the human organism.

\section{Conclusions}

The penetration of foreign molecules through a polymer membrane starts from a transient process, which establishes an equilibrium between the boundary layer of the membrane and the environment. This process looks like damped oscillations induced by the instability of ball-shaped chains in the boundary layer. Namely, if the external pressure changes, the chain shape begins to transform periodically: the ball-like chains periodically transform into the globular ones and vice versa. As a result, the concentration of foreign molecules and their pressure in the boundary layer change periodically.

The transient process period is determined by the damping time of self-oscillations. The latter decreases with the increasing temperature due to the absorption of the energy of oscillations in the environment. The transient processes in the synthetic and biological membranes have the same origin. Since this process is invoked by the shape instability of the chains, it may be started by small variations of the external pressure. Therefore, it can be considered as one of the possible processes that determine the action of changes in the atmospheric pressure on the human organism.

The transient process is the initial stage of the penetration of foreign molecules into the membrane. The next stage is the diffusion of foreign molecules through the membrane region located behind the 
boundary layer. The duration of the transient process is much shorter than the characteristic diffusion time, which makes valid the thermodynamic description of the transient process.

1. N.V. Yarovaya, V.I. Shtompel, T.S. Ivanova et al. Effect of isomerism on the polymerization kinetics of oligo-urethane acrylates and the formation of supramolecular structures. In Proceedings of the International Scientific and Technical Conference "Polykon 98", Gomel, Belarus (1998), p. 242 .

2. L.D. Landau and E.M. Lifshitz, Statistical Physics, Part 1 (Pergamon Press, 1980).

3. L.A. Bulavin, Yu.F. Zabashta, O.S. Svechnikova. Polymer Physics (Kyiv University Publ. House, 2004) (in Ukrainian).

4. A.Yu. Grosberg, A.R. Khokhlov. Statistical Physics of Macromolecules (American Institute of Physics, 1994).

5. L.D. Landau, E.M. Lifshitz, Fluid Mechanics (Pergamon Press, 1993).
6. S. Reitzma. The endothelial glycocalyx: Composition, functions, and visualization. Europ. J. Physiol. 454, 345 (2007).

Received 23.06.17.

Translated from Ukrainian by O.I. Voitenko

Л.А. Булавін, Л.Ю. Вергун,

Ю.Ф. Забашта, О.С. Свечнікова

МЕХАНІЗМ ВЗАЄМОДІЇ ПРИМЕЖОВОГО ШАРУ

ПОЛІМЕРНИХ МЕМБРАН ІЗ ГАЗОВИМ ОТОЧЕННЯМ

Р е з ю м е

Експериментально досліджено початковий етап проникливості молекул повітря через полімерну мембрану. Виявлено, що на цьому етапі відбувається перехідний процес, який є процесом встановлення рівноваги між газом і примежовим шаром мембрани. Цей процес носить характер затухаючих коливань, спричинених періодичною зміною форми полімерних ланцюгів у примежовому шарі, пов'язаною із переходами "клубок-глобула". Висловлено гіпотезу про те, що аналогічне явище $є$ однією з причин, що зумовлює вплив змін атмосферного тиску на організм людини. 